\title{
PREDICTING THE SEISMIC BEHAVIOUR OF THE FOUNDATIONS OF THE MESSINA STRAIT BRIDGE
}

\author{
Sebastiano RAMPELLO ${ }^{1}$, Luigi CALLISTO ${ }^{1}$, Giulia VIGGIANI ${ }^{2}$
}

(1) Prof. S. Rampello, Sapienza University of Rome, Dept. of Structural and Geotechnical Engineering, sebastiano.rampello@uniroma1.it

(2) Prof. L. Callisto, Sapienza University of Rome, Dept. of Structural and Geotechnical Engineering, luigi.callisto@uniroma1.it

(3) Prof. G. Viggiani, University of Rome Tor Vergata, Dept. of Civil Engineering, viggiani@uniroma2.it

Corresponding Author:

Prof. Sebastiano Rampello

Dept. of Structural and Geotechnical Engineering

Via Eudossiana 18

00184 - Roma - Italy

Tel.: +390644585989

Fax: +390644584792

e-mail: sebastiano.rampello@uniroma1.it 


\begin{abstract}
This paper presents some of the geotechnical studies carried out for the seismic design of the one-span suspension bridge across the Messina Strait, which is to connect Sicily with mainland Italy. These studies included advanced geotechnical characterisation, through in situ and laboratory tests, estimate of site stability involving both liquefaction analysis and submerged slope stability, evaluation of soil-foundation stiffness for spectral analysis of the superstructure, 3D FE static calculations, evaluation of anchor block performance under seismic conditions, and full dynamic analyses of the soil-structure interaction. The paper summarises the main results obtained from the geotechnical characterisation of the foundation soils, reports the approach adopted for evaluating the seismic performance of the anchor blocks through a modified Newmark-type calculation, and presents the study of the soilstructure interaction carried out through a series of two-dimensional, plane strain numerical analyses. In these analyses, in addition to the embedded foundation elements, the models included a simplified structural description of the bridge towers specifically designed to reproduce their first vibrations modes, which were deemed to have the most significant influence on the system's dynamic response. The illustration is limited to the foundation systems of the bridge located on the Sicily shore.
\end{abstract}

Keywords: bridge foundations, seismic design, displacement-based analysis, dynamic analysis 


\section{INTRODUCTION}

The seismic behaviour of the foundation system of the Messina Strait Bridge was studied using a hierarchical approach that entailed the development of a number of analyses with increasing levels of complexity, and of corresponding strategies to approximate the coupling between the behaviour of the soil, the foundation systems and the superstructure.

The subsoil consists primarily of coarse-grained soils (sandy gravels) that, on the Calabria side, rest on top of a soft conglomerate named Pezzo Conglomerate. In addition to many other geotechnical investigations and in situ testing, monotonic and cyclic triaxial tests were carried out on undisturbed samples retrieved from the gravelly deposit with the freezing technique. The results of these tests provided the shear strength parameters and were used for the assessment of the liquefaction resistance, not discussed in this paper for sake of space.

The study of the seismic performance of the foundations was first carried out evaluating the dynamic impedance of each foundation element, regarded as a macro-element embedded in a visco-elastic medium, and including these impedances in a spectral analysis of the global model of the superstructure. The maximum seismic loads computed at the foundation level by the spectral analyses were then applied to static three-dimensional finite element models of the foundation elements embedded into the soil. These analyses were mainly aimed to ascertain that the global soil resistance is not attained during the design earthquake.

Permanent displacements induced in the anchor blocks by the earthquake were computed with time-domain analyses that employed the rigid-block Newmark approach, modified in order to account for the progressive mobilisation of the passive resistance in front of the anchor blocks. These analyses were repeated for a large number of seismic records, even more severe than the design earthquake, in order to get an appreciation of the dependence of the seismic performance on the properties of the seismic input.

Finally, a set of dynamic numerical analyses was carried out, in which the soil behaviour was represented with an hysteretic constitutive model coupled with a Mohr-Coulomb failure criterion. A set of equivalent plane-strain models were developed, that included the static loads and a simplified representation of the bridge structure, aimed to reproduce its most significant vibration modes. This can be regarded very closely as a fully coupled soil-structure interaction analysis, which provided a better appreciation of the seismic performance of the foundation system. The results of the analysis were used to assess the seismic performance of the bridge foundations; they could also be transferred back to the structural global model of the bridge for additional time-domain structural analyses that implicitly account for soilstructure interaction.

The following sections illustrate, after an introductory description of the bridge substructures and a discussion of the geotechnical properties of the foundation soils, the development of the 
calculation models that were used for evaluating the behaviour of the bridge foundations. For sake of conciseness, and to avoid unnecessary repetition, the illustration is mostly limited to the foundation systems located on the Sicily shore.

\section{GEOTECHNICAL CHARACTERISATION AND FOUNDATION LAYOUT}

In the project finalised in 2011 by the General Contractor Eurolink, the suspension bridge over the Messina Strait has a span length of $3.3 \mathrm{~km}$ with a distance between the anchor blocks and the towers of $960 \mathrm{~m}$ on the Sicily shore and of $810 \mathrm{~m}$ on the Calabria shore. The bridge towers have a height of $399 \mathrm{~m}$ od (Fig. 1).

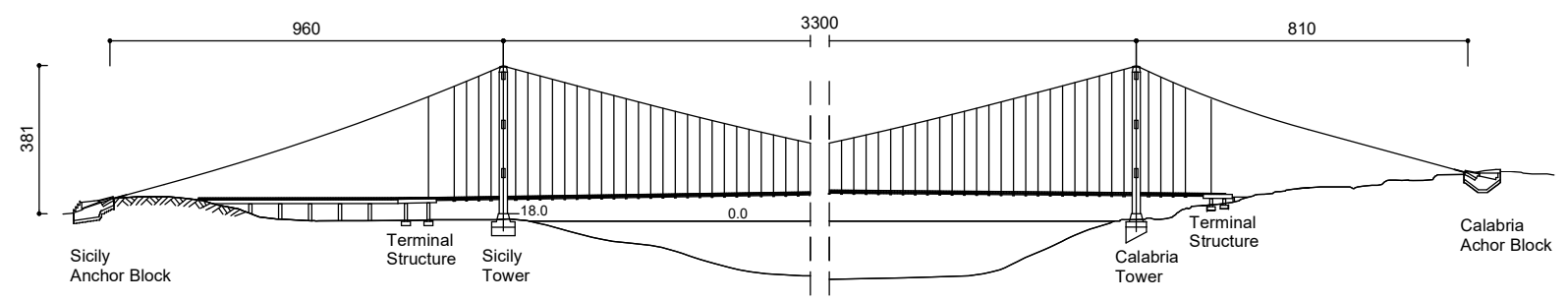

Figure 1. Single span suspension bridge of Messina Strait

Figure 2 shows a soil profile for the Sicily shore where the anchor block and the foundations of the tower and of the terminal structure are highlighted. At the depths of interest for the foundation systems the foundation soil consists of medium-coarse granular materials: the Coastal Deposits and the Messina Gravel. Coastal Deposits are made by sand and gravel with little fine content, with a thickness that varies from about $80 \mathrm{~m}$ at the tower location to about $45 \mathrm{~m}$ at the terminal structure. Messina Gravel consists of gravel and sand with very occasional silty levels; at the tower location, this deposit is found below the Coastal Deposits and has a thickness of about $144 \mathrm{~m}$, while at the anchor block location it is present from the ground surface down to a depth of about $214 \mathrm{~m}$.

The Coastal Deposits and the Messina Gravel are characterised by similar grading but different geological history; the contact between these two deposit was detected using mainly the results of cross-hole tests, that revealed an appreciable increase of the shear wave velocity in the Messina Gravel, that can be related to a weak $\mathrm{CaCO}_{3}$ inter-particle bonding.

Figure 3 shows a plan view of the foundations of the Sicily tower, together with the in situ investigations carried out in the years 1988-1992 and in 2010. The tower foundations, located at a minimum distance of about $30 \mathrm{~m}$ from the sea, consist of two $20 \mathrm{~m}$ deep embedded cylindrical footings, with a diameter of $55 \mathrm{~m}$ and a centre-to-centre distance of $77.5 \mathrm{~m}$. 

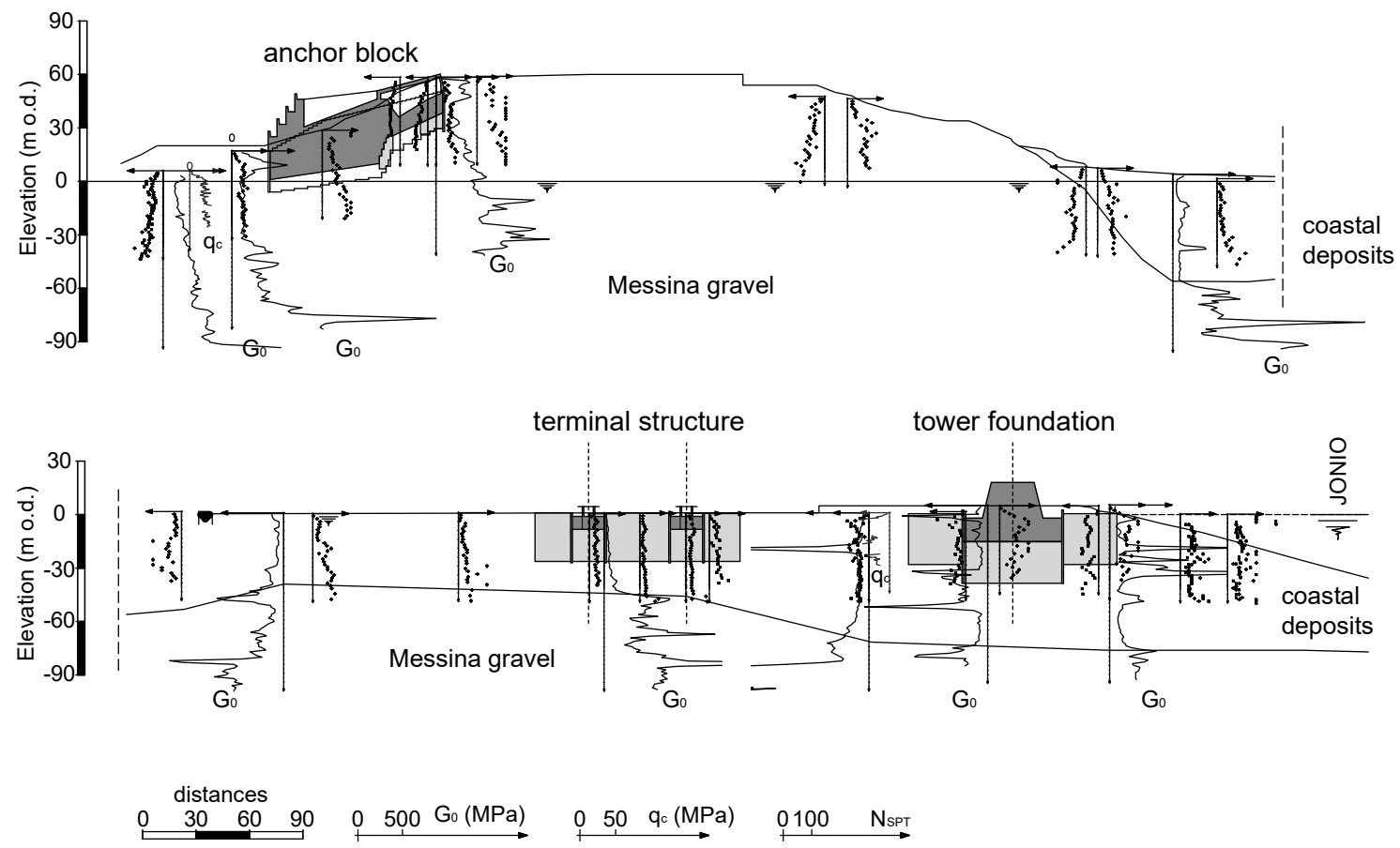

Figure 2. Soil profile on Sicily shore

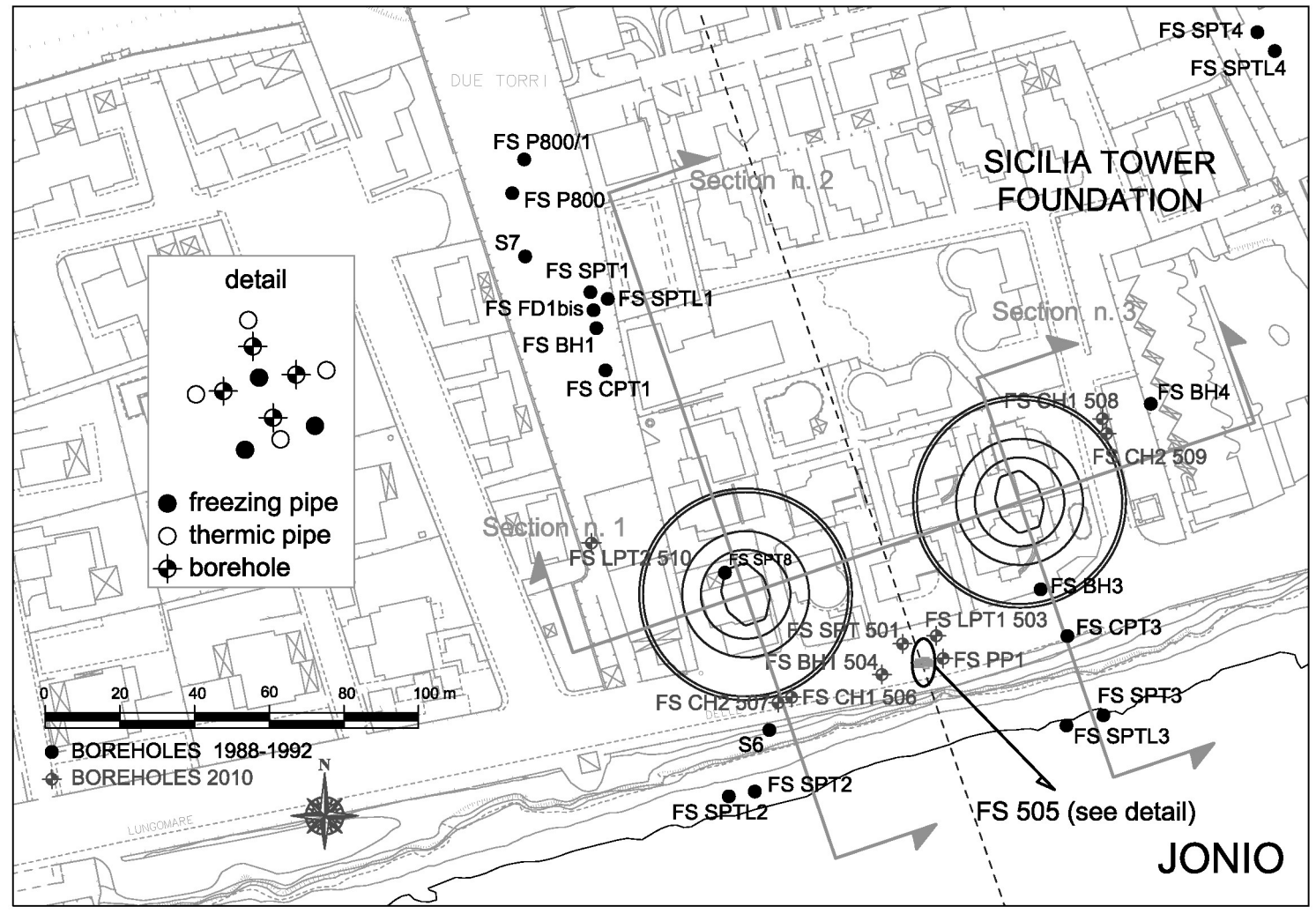

Figure 3. Geotechnical investigation at Sicily tower location 
The geotechnical investigation consisted mainly of standard penetration tests (SPT) and large penetration tests (LPT) (Jamiolkowski and Lo Presti, 2002), carried out at intervals of $1.5 \mathrm{~m}$ down to a depth of $50 \mathrm{~m}$; cross-hole tests $(\mathrm{CH})$ performed to a depth of $100 \mathrm{~m}$; well pumping tests; and Lefranc tests. Reconstituted samples were also retrieved from $100 \mathrm{~m}$-long largediameter boreholes, while a limited number of large-diameter $(D=0.30 \mathrm{~m})$ undisturbed samples were retrieved by means of the in situ freezing technique at depths of 15 to $25 \mathrm{~m}$. The in situ freezing site was located in the middle section between the tower footings, on the sea side. It consisted of 3 freezing pipes installed in a triangular array with a spacing of about 1.2 m, 4 boreholes and 4 pipes for temperature measurements (see the insert in Fig. 3).

Using the velocity of the compression waves $V_{\mathrm{p}}$ measured in the cross-hole tests, the porosity $n$ of fully saturated soils could be evaluated as (Foti at al. 2002):

$$
n=\frac{\rho_{s}-\left[\rho_{\mathrm{s}}^{2}-\frac{4\left(\rho_{\mathrm{s}}-\rho_{\mathrm{f}}\right) \cdot K_{\mathrm{f}}}{V_{\mathrm{P}}^{2}-2 \cdot\left(\frac{1-v_{\mathrm{s}}}{1-2 v_{\mathrm{s}}}\right)}\right]^{0.5}}{2\left(\rho_{\mathrm{s}}-\rho_{\mathrm{f}}\right)}
$$

where $\rho_{\mathrm{s}}\left(=2.67 \mathrm{Mg} / \mathrm{m}^{3}\right)$ is the mass density of the soil particles; $\rho_{\mathrm{f}}\left(=1.0 \mathrm{Mg} / \mathrm{m}^{3}\right)$ is the mass density of the pore fluid, $K_{\mathrm{f}}(=2.15 \mathrm{GPa})$ is the bulk modulus of the pore fluid and $v_{\mathrm{s}}=0.2$ is the Poisson's ratio of the soil skeleton. This information was then used to calculate the unit weight $\gamma$ and the void index $e$.

As mentioned above, the increase in the shear wave velocity observed in the $\mathrm{CH}$ tests also permitted to identify the contact between the Coastal Deposits and the Messina Gravel on the Sicily shore, as well as between the weathered and the undisturbed Pezzo Conglomerate on the Calabria shore.

Figure 4 shows the example of a cross-hole test carried out at the location of the terminal structure. The contact between the Coastal Deposits and the Messina Gravel is marked by the increase in shear wave velocity at a depth of $45 \mathrm{~m}$. The computed unit weight and void ratio are about constant with depth in the two layers, with higher values of $\gamma\left(24 \mathrm{kN} / \mathrm{m}^{3}\right)$ and lower values of $e(0.3)$ in the Messina Gravel.

The results of three $\mathrm{CH}$ tests carried out at the tower location are plotted in terms of smallstrain shear modulus $G_{0}$ in Figure 5. In this case, the contact of the Coastal Deposits with the Messina Gravel is found at a depth of about $80 \mathrm{~m}$; values of $G_{0}$ are in the range of 100 to $250 \mathrm{MPa}$ in the Coastal Deposits, with the exception of local increases between 15 and $40 \mathrm{~m}$ 
of depth, while $G_{0}$ is larger than $450 \mathrm{MPa}$ in the Messina Gravel. The same figure also shows three values of $G_{0}$ obtained from bender element (BE) tests carried out in the laboratory on large-diameter undisturbed samples retrieved with the in situ freezing technique.
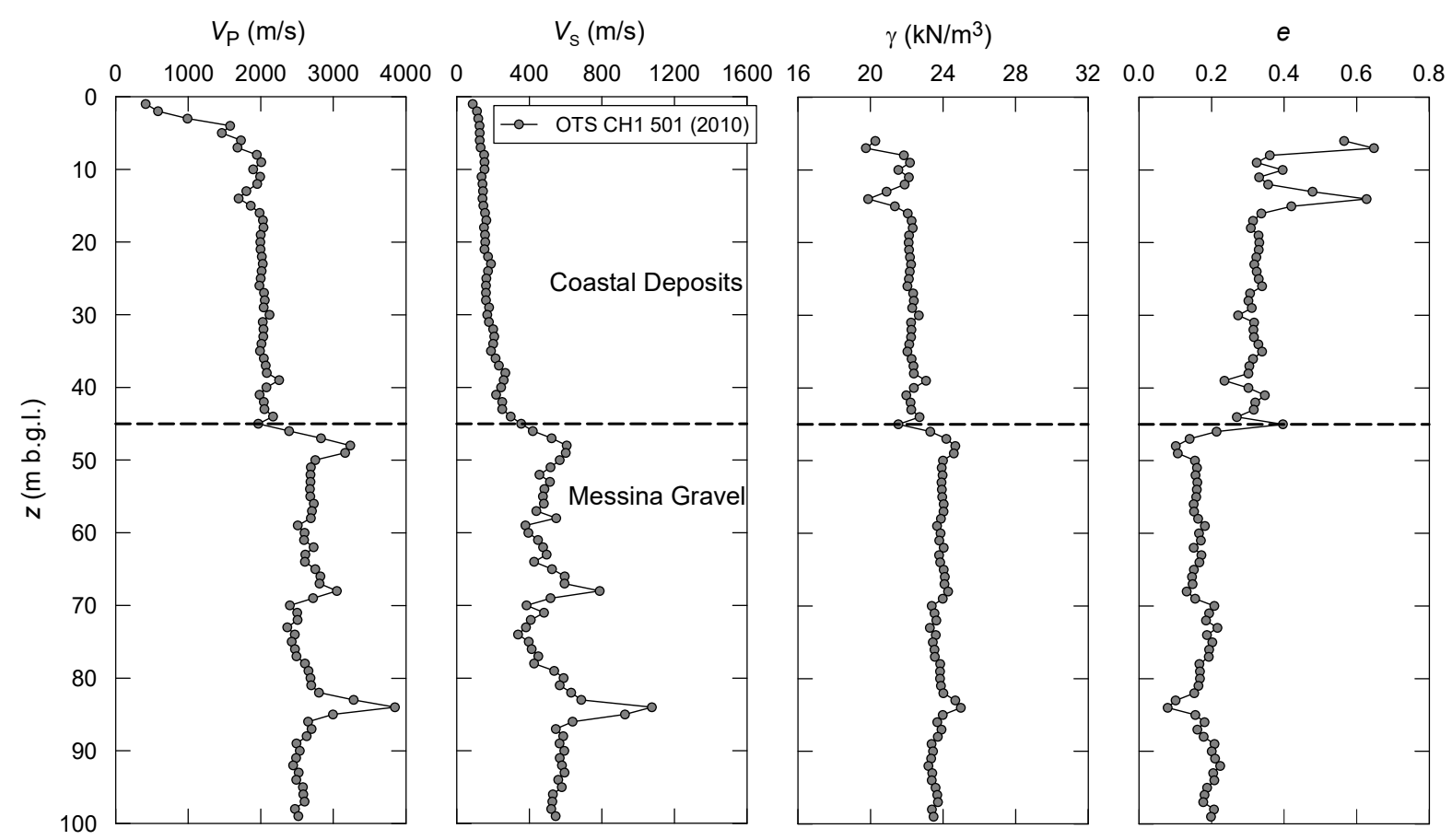

Figure 4. Terminal structure location: profiles of unit weight and void ratio from cross-hole tests

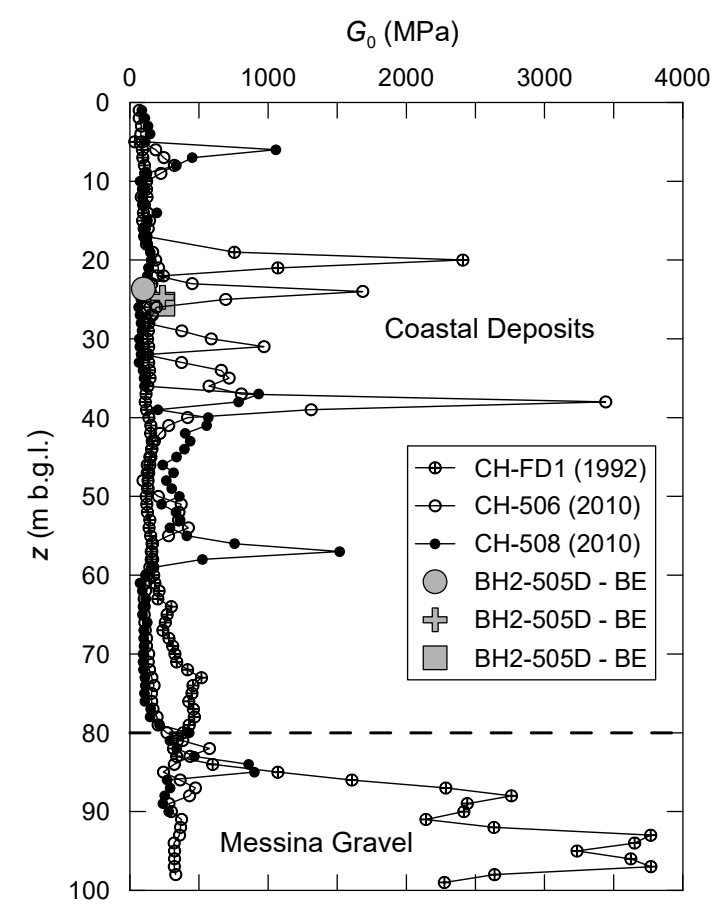

Figure 5. Sicily tower location: profiles of small-strain shear modulus 
The good agreement between the values of $G_{0}$ from BE tests and $\mathrm{CH}$ tests confirms the high quality of the undisturbed samples. A similarly good agreement is shown by Fioravante et al. (2012) on the same soils.

The shear strength of the foundation soils was evaluated using the results of both in situ and laboratory tests. Results of standard and large penetration tests were used for evaluating the relative density $D_{\mathrm{R}}$ and the angle of shearing resistance at peak $\varphi_{\mathrm{p}}^{\prime}$. The relative density was estimated following the procedure proposed by Cubrinovski and Ishihara (1999):

$$
D_{\mathrm{R}}=\left[\frac{\left(N_{1}\right)_{78}}{C_{\mathrm{d}}}\right]^{0.5}
$$

where:

$$
\left(N_{1}\right)_{78}=\frac{E R}{78} \cdot N_{\mathrm{SPT}}\left(\frac{p_{\mathrm{a}}}{\sigma_{\mathrm{v} 0}^{\prime}}\right)^{0.5}
$$

is the $N_{\mathrm{SPT}}$ blow count normalized to account for the overburden stress $\sigma^{\prime}{ }_{\mathrm{v} 0}$ and the energy ratio $E R$ measured during the tests using a load cell installed below the hammer. An energy ratio of $78 \%$ was adopted for normalisation as the procedure was calibrated using tests performed according to the Japanese standard. The other quantities defining $D_{\mathrm{R}}$ are:

$$
c_{\mathrm{d}}=\frac{9}{\left(e_{\max }-e_{\min }\right)^{1.7}}
$$

and

$$
\left(e_{\max }-e_{\min }\right)=0.23+\frac{0.06}{D_{50}}
$$

$c_{\mathrm{d}}$ is a parameter linked to the void ratio potential $\left(e_{\max }-e_{\min }\right)$ that in turn is related to the mean particle size $\left(D_{50}\right)$. Average values of $D_{50}$ equal to $2.0 \mathrm{~mm}$ and $2.7 \mathrm{~mm}$ were selected from the results of grading analyses for the Coastal Deposits at the tower location and for the Messina Gravel at the anchor block location, respectively.

The angle of shearing resistance at peak $\varphi_{\mathrm{p}}^{\prime}$ was computed as a function of the relative density and of the mean effective stress using the relationship proposed by Bolton (1986):

$$
\begin{aligned}
& \varphi_{\mathrm{p}}^{\prime}-\varphi_{\mathrm{cV}}^{\prime}=3 \cdot\left[D_{\mathrm{R}}\left(10-\ln p_{\mathrm{f}}^{\prime}\right)-1\right] \quad\left(\text { for } p_{\mathrm{f}}^{\prime} \geq 150 \mathrm{kPa}\right) \\
& \varphi_{\mathrm{p}}^{\prime}-\varphi_{\mathrm{cV}}^{\prime}=3 \cdot\left[D_{\mathrm{R}}(5)-1\right] \quad\left(\text { for } p_{\mathrm{f}}^{\prime}<150 \mathrm{kPa}\right)
\end{aligned}
$$

in which $p_{\mathrm{f}}^{\prime}$ is the mean effective stress at failure at the depth of the SPT measurements. 
The friction angle at constant volume $\varphi_{\mathrm{cv}}^{\prime}$ was obtained from the results of drained triaxial compression tests carried out on large-diameter $(D=0.30 \mathrm{~m})$ reconstituted samples, retrieved at depths of 4 to $55 \mathrm{~m}$ and prepared in the laboratory at values of relative density $D_{\mathrm{R}}=40 \%$, $60 \%$ and $80 \%$. These tests provided a well defined strength envelope with a friction angle at constant volume $\varphi^{\prime}{ }_{\mathrm{cv}}=38^{\circ}$ (Fig. $\left.6 \mathrm{a}\right)$.

Figure $6 \mathrm{~b}$ shows the profiles of the relative density $D_{\mathrm{R}}$ and of the angle of shearing resistance at peak $\varphi_{p}^{\prime}$ evaluated in the Coastal Deposits at the Sicily tower location. A slight decrease of relative density with depth is observed with values of $D_{\mathrm{R}}$ of 60 to $40 \%$ in the upper $25 \mathrm{~m}$, and mostly in the range of 50 to $30 \%$ at larger depths. The full triangles in Figure $6 \mathrm{~b}$ also show some values of $D_{\mathrm{R}}$ obtained using the in situ void ratio from the $\mathrm{CH}$ tests and the values of $e_{\max }$ and of the $e_{\min }$ from laboratory tests; these data are in good agreement with the values computed using the procedure by Cubrinovski and Ishihara (1999).

The angle of shearing resistance at peak shows a gentle decrease with depth resulting from the combined effect of a decrease of relative density and an increase of mean effective stress with depth. Specifically, $\varphi_{\mathrm{p}}^{\prime}$ decreases from about $45^{\circ}$ to about $40^{\circ}$ in the top $25 \mathrm{~m}$, while at larger depths it tends progressively to the constant-volume value of $38^{\circ}$. The cyclic undrained triaxial tests performed on large-diameter undisturbed samples provided values of the angle of shearing resistance at peak $\varphi_{\mathrm{p}}^{\prime}=40^{\circ}-44^{\circ}$ that are consistent with the range of $\varphi_{\mathrm{p}}^{\prime}$ values obtained from in situ tests, in the same interval of depths $(15-25 \mathrm{~m})$.
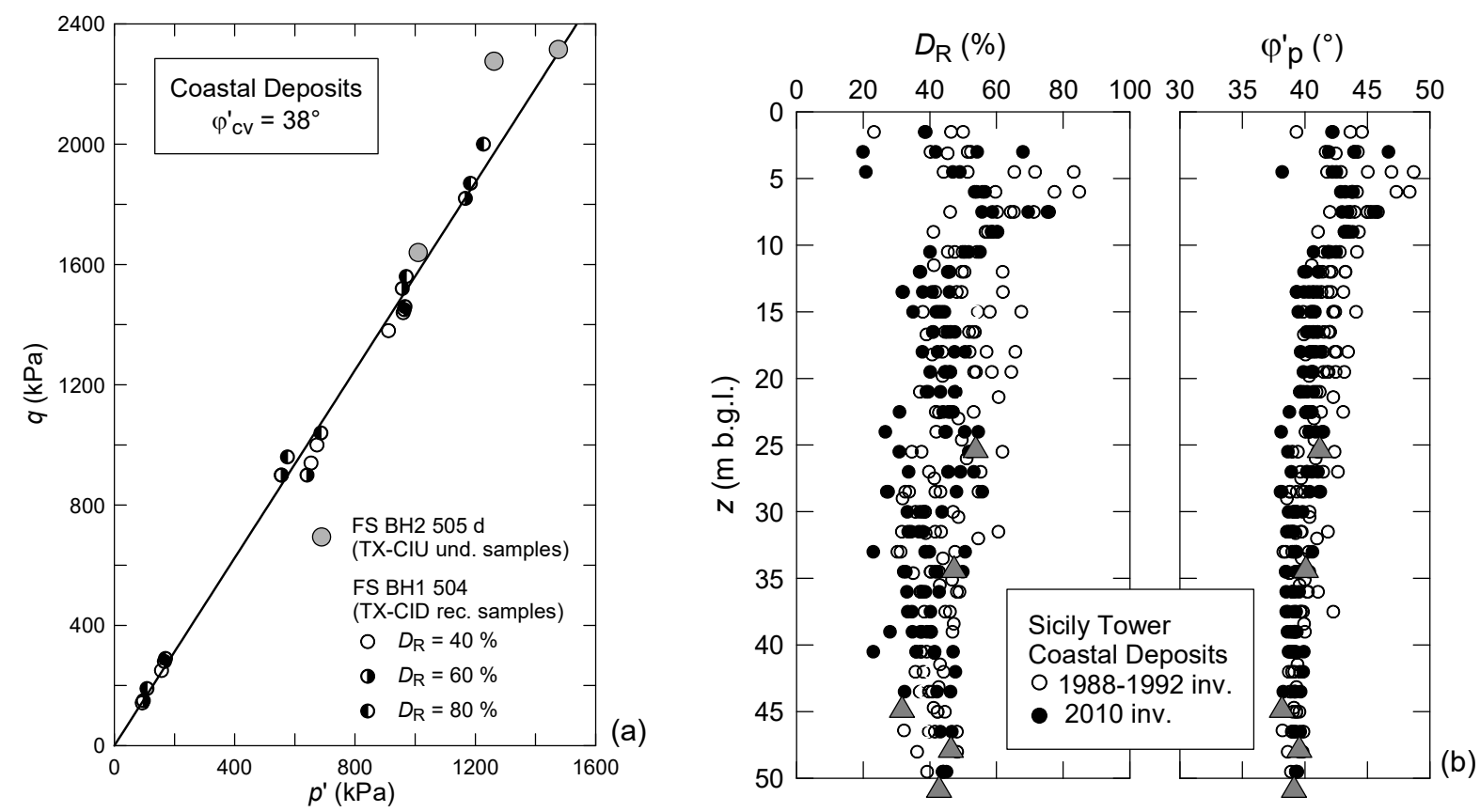

Figure 6. Sicily tower location: (a) constant-volume strength envelope from triaxial compression tests; (b) profiles of relative density and peak friction angle from dynamic penetration tests 
In situ and laboratory tests then provided consistent results, confirming the good reliability of the geotechnical investigations carried out at the site.

\section{EVALUATION OF ANCHOR BLOCKS BEHAVIOUR}

\subsection{Safety checks at maximum loads computed from spectral analyses of the superstructure}

The seismic behaviour of the bridge foundations was evaluated using different strategies to approximate the coupling between the soil, the foundations and the superstructure. For the anchor blocks, 3D FE static analyses were first carried out. Due to the very large natural period of the cables, it could be assumed that the anchor block elements were loaded by a static force progressively increasing up to the value that produced full mobilization of the soil strength. These computations represent a sort of push-over analyses, providing the loads associated to block sliding, together with information about the progressive mobilization of the soil strength with increasing loads; the results of the analyses were also useful to estimate the average inclination of the sliding mechanism activated by the cable forces, used at a later stage in Newmark-type computation of seismic displacements.

The shape of the Sicily anchor block in plan is trapezoidal, with a length of $100 \mathrm{~m}$ long and transverse minimum and maximum widths of $80 \mathrm{~m}$ and $120 \mathrm{~m}$, respectively. In section, the block has a wedge-like shape with a base inclined of about $25^{\circ}$ at the front and of about $8^{\circ}$ at the rear (Fig. 7). Its construction requires excavation depths of 20 to $33 \mathrm{~m}$. The anchor block includes 4 splay chambers: 2 of them are for the main cables, while the other 2 are to be filled with granular material after cable installation (ballast chambers). The total weight of Sicily anchor block is $W=7502 \mathrm{MN}$.

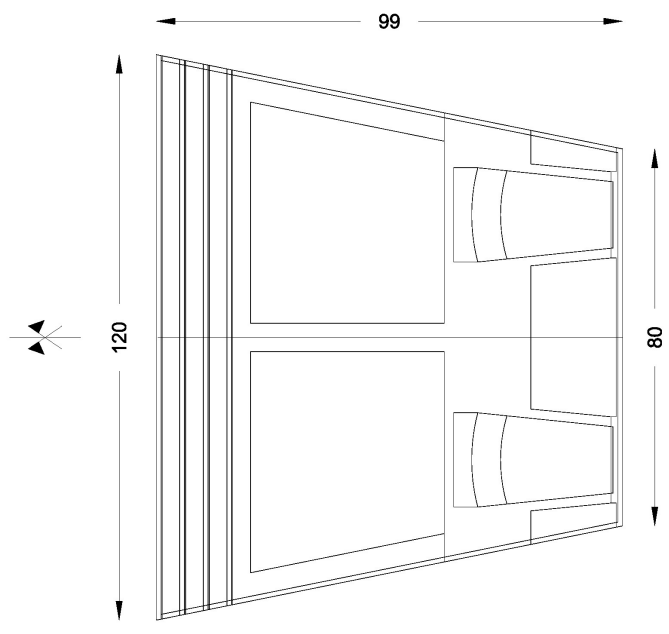

(a)

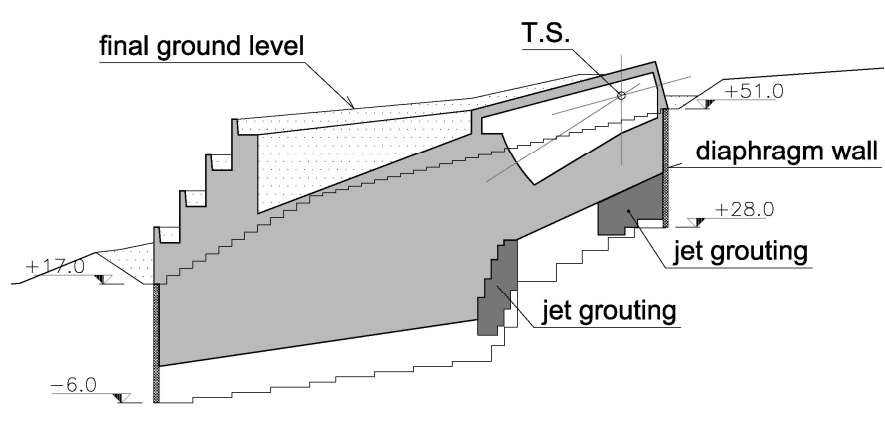

Figure 7. Plan view and longitudinal section of Sicily anchor block 
The 3D FE static analyses were carried out in terms of effective stresses modelling the granular soils as drained; they were carried out with the finite element code Plaxis 3D Foundation describing the mechanical behaviour of the foundation soils with the Hardening Soil model (Schanz et al., 1999). This is an elastic-plastic rate independent constitutive model, with isotropic hardening and Mohr Coulomb failure criterion, capable to reproduce the non-linear stress-strain behaviour due to the development of plastic strains from the beginning of a loading process. In the model, the elastic behaviour is defined by isotropic elasticity using a stress dependent Young's modulus:

$$
E^{\prime}=E^{\mathrm{ref}}\left(\frac{c^{\prime} \cdot \cot \varphi^{\prime}+\sigma_{3}^{\prime}}{c^{\prime} \cdot \cot \varphi^{\prime}+p^{\mathrm{ref}}}\right)^{\mathrm{m}}
$$

where $\sigma_{3}^{\prime}$ is the minimum principal effective stress, $c^{\prime}$ is the effective cohesion, $\varphi^{\prime}$ is the angle of shearing resistance and $p^{\text {ref }}=100 \mathrm{kPa}$ is a reference pressure; $E^{\text {ref }}$ and $m$ are model parameters. The elastic Young's modulus, that describes the loading-unloading stiffness, was related to the small-strain shear modulus $G_{0}$ obtained from cross-hole tests: values of $E^{\text {ref }}$ and $m$ were obtained by best fitting the cross-hole test results using equation (7) and assuming $v^{\prime}=0.2$.

Table 1. Input parameters for static FE analyses of Sicily anchor block behaviour

\begin{tabular}{c|c|c|c|c|c|c|c|c}
\hline $\begin{array}{c}\text { Messina } \\
\text { Gravel }\end{array}$ & $\begin{array}{c}\gamma \\
(\mathrm{kN} / \mathrm{m} 3)\end{array}$ & $\begin{array}{c}\varphi^{\prime} \\
\left({ }^{\circ}\right)\end{array}$ & OCR & $K_{0}$ & $\begin{array}{c}E^{\prime}{ }^{\text {ref }} \\
(\mathrm{MPa})\end{array}$ & $m$ & $\begin{array}{c}E^{\prime}{ }^{\text {ref }} \\
(\mathrm{MPa})\end{array}$ & $\begin{array}{c}E_{\text {'oed }}^{\prime \text { ref }} \\
(\mathrm{MPa})\end{array}$ \\
\hline$>75$ od & 20.0 & 42 & 2.0 & 0.47 & 408 & 0.6 & 20.4 & 20.4 \\
$<75$ od & 20.0 & 42 & 2.0 & 0.47 & 1080 & 0.1 & 54.0 & 54.0 \\
\hline
\end{tabular}

In the area of the Sicily anchor block the Messina Gravel can be assumed to be nearly normally consolidated, so that $K_{0}$ can be estimated using the relationship proposed by Baldi $e t$ al. (1985) that, for values of relative density $D_{\mathrm{R}}=40-50 \%$, provides a coefficient of earth pressure at rest $K_{0} \cong 0.47$.

The model has a deviatoric $\left(f_{\mathrm{s}}\right)$ and a volumetric $\left(f_{\mathrm{v}}\right)$ yield surfaces with independent isotropic hardening depending on deviatoric plastic strain $\gamma^{\mathrm{p}}$ and volumetric plastic strain $\varepsilon_{\mathrm{v}}{ }^{\mathrm{p}}$. The deviatoric hardening rule is related to parameter $E^{\prime}{ }_{50}$, while the volumetric hardening rule is controlled by parameter $E^{\prime}{ }_{\text {oed. }}$. The dependence of both on the state of effective stress is described by expression similar to equation (7) but, in contrast to $E^{\prime}$, they are not used within a concept of elasticity. The flow rule is associated for states lying on the surface $f_{\mathrm{v}}$, while a non-associated flow rule is used for states on the surface $f_{\mathrm{s}}$. 
Despite the soil being normally consolidated, values of $O C R>1$ were adopted in the numerical analyses for the sole purpose of avoiding the use of a plasticity cap in the modelling of a coarse-grained material. Table 1 lists the soil parameters employed in the analyses.

Figure 8a shows the profiles of $G_{0}$ obtained from two cross-hole tests carried out at the location of the Sicily anchor block. The continuous line in the figure represents the profile of $G_{0}$ used in the FE analyses, computed using the parameters of Table 1. Non linear stressstrain behaviour is described in the model by parameters $E^{\prime}{ }_{50}$ and $E^{\prime}{ }_{\text {oed }}$ that were evaluated by best fitting the shear modulus decay obtained by Tanaka et al. (1987) for reconstituted gravelly soils with a gravel content of $50 \%$ under a confining effective stress of $200 \mathrm{kPa}$. A fair agreement between observed and computed stress-strain relationships was obtained using the parameters listed in Table 1 (Fig. 8b).
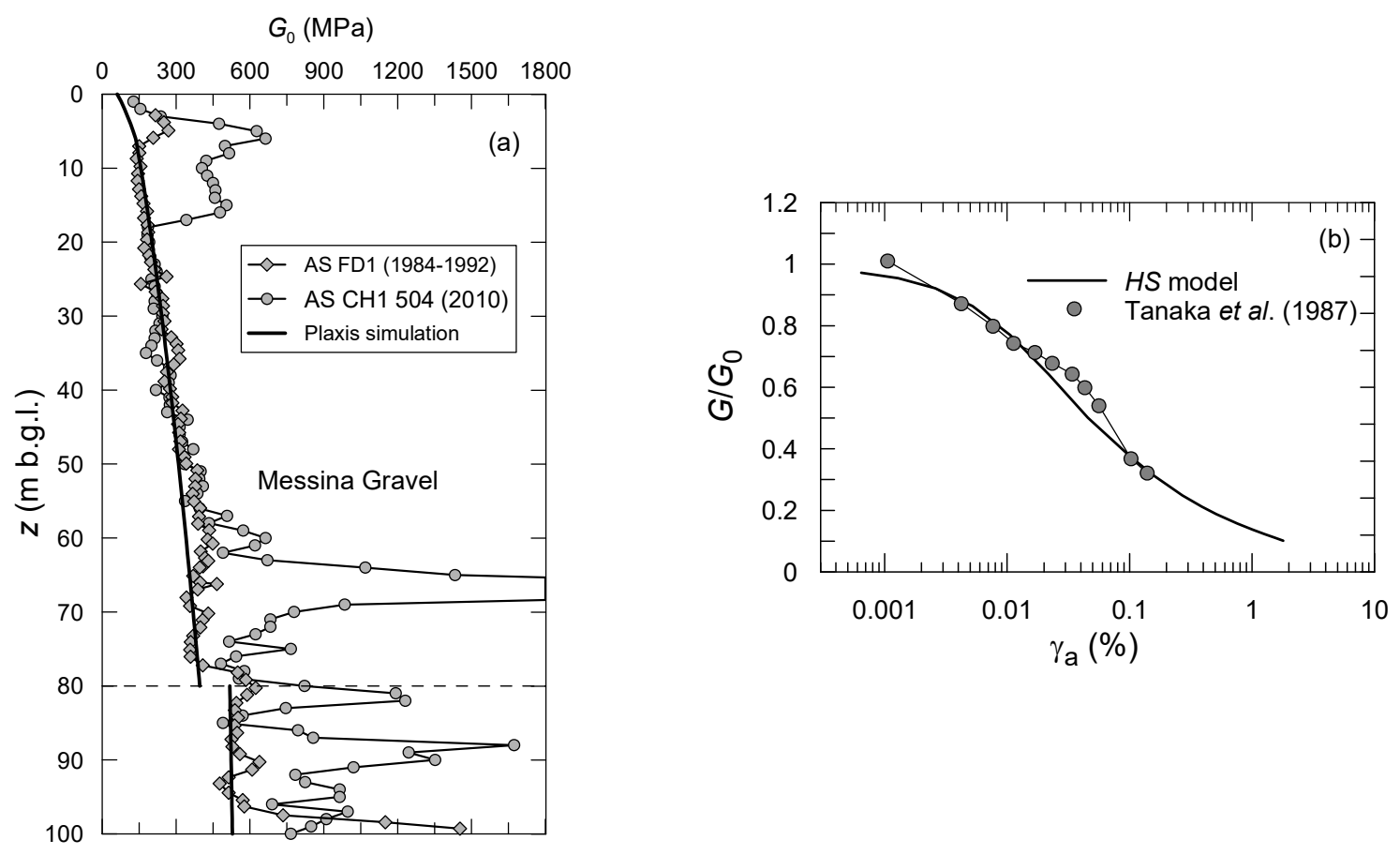

Figure 8. Sicily anchor block : calibration of shear modulus profile at small-strain and of stress-strain behaviour

Figure 9a shows a 3D view of the analysis domain in which the construction area of the anchor block can be recognised. The FE mesh is $400 \mathrm{~m}$ long in the longitudinal direction, 450 $\mathrm{m}$ wide in the transverse direction and $150 \mathrm{~m}$ deep from the upper ground level, at $56 \mathrm{~m}$ od. The construction sequence was modelled in the analysis to reproduce the effective stress state of the soil after block construction. To this purpose the earth retaining structures, needed to 
support the excavation area, were explicitly included in the model (Fig. 9b). The retaining system consisted of diaphragm walls, of lengths variable between 23 and $40 \mathrm{~m}$, and of 8 levels of pre-stressed anchors modelled with pre-stressed elastic-perfectly plastic springs.

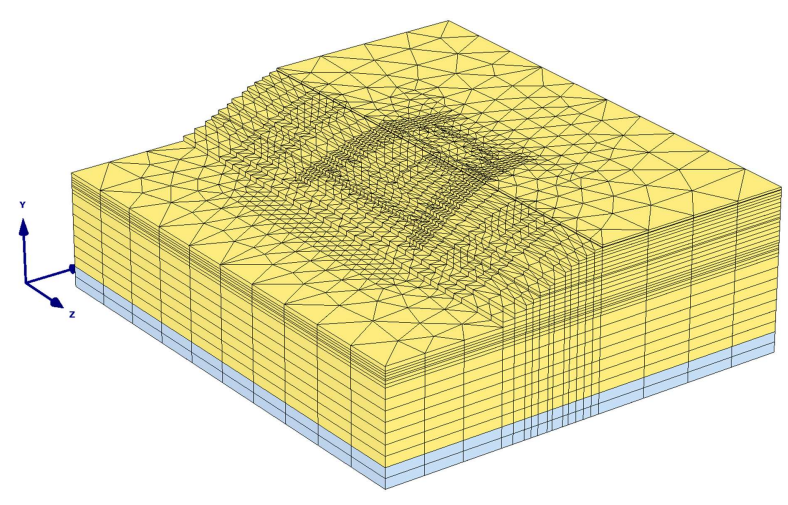

(a)

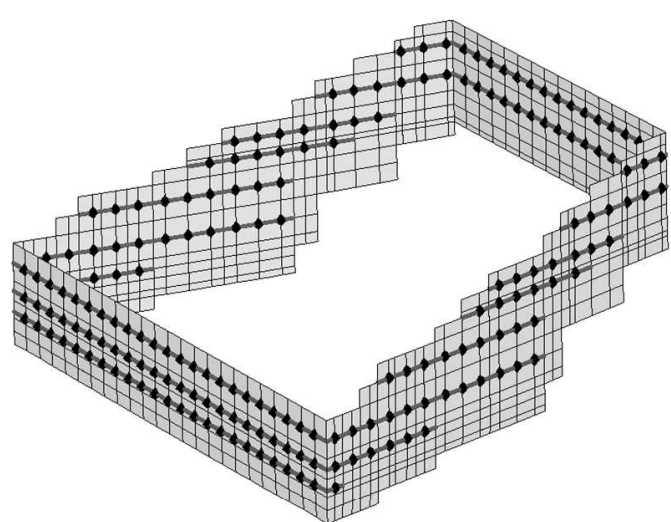

(b)

Figure 9. Sicily anchor block: (a) 3D view of the analyses domain; (b) detail of retaining diaphragm walls included in the model to reproduce the excavation stage of block construction

The numerical analyses included: computation of the initial effective stresses; modelling of a pre-excavation stage needed to reach the installation depth of the diaphragm walls; activation of the diaphragm walls and of the jet-grouted areas; progressive excavation of the area and simultaneous activation of the pre-stressed anchors; progressive construction of the block through the activation of concrete layers about $3 \mathrm{~m}$ thick.

To reproduce the lateral pressure acting on the diaphragm walls, for each construction stage a layer of fluid concrete was activated first, with a very low Young's modulus and a Poisson's ratio of about 0.5 , changing the properties of the layer to those of solid concrete before adding the subsequent layer of concrete. At the end of construction, the pre-excavated area was filled together with the ballast chambers, and the cable forces were progressively increased.

The plot of Figure 10 shows the cable forces plotted as a function of the total displacements computed at the 10 nodes shown in the insert, located along the block boundary and at its centre. Under static conditions, an ultimate condition is evaluated for a cable force about 4 times larger than that corresponding to the design ultimate limit state, evaluated through a spectral analysis of the global bridge model. The displacement field induced by cable forces mainly consists of a translation towards the tower, associated with a slight downward rotation. Inspection of the displacement vectors reveals that the displacement field can be regarded as a translation along a plane characterised by an average inclination of about $14^{\circ}$, associated with a slight rotation (about $0.03^{\circ}$ ) about the centre of gravity. 


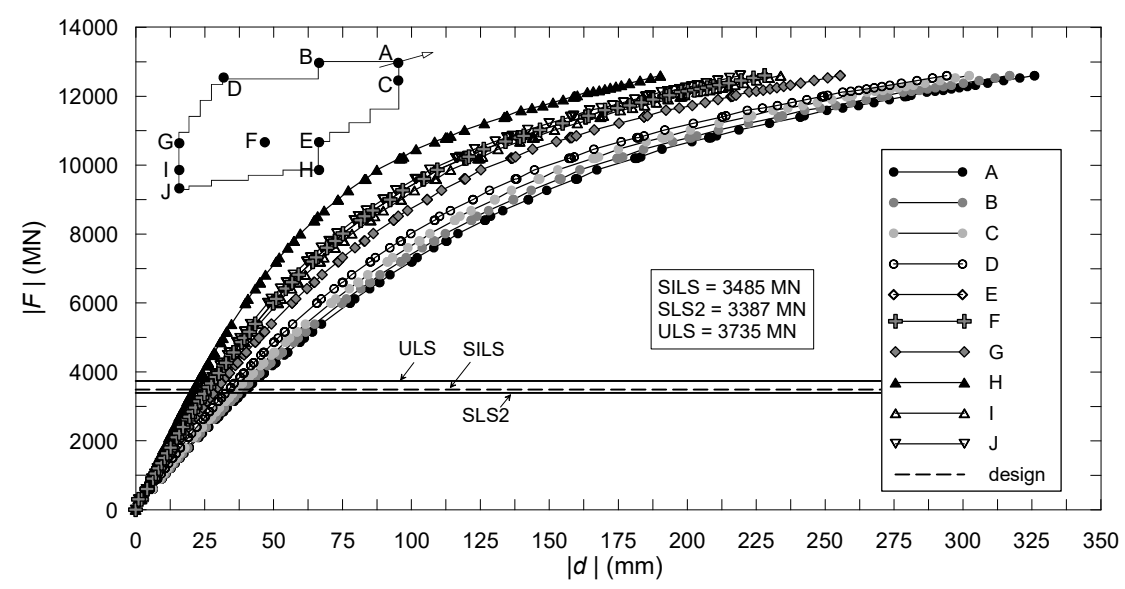

Figure 10. Sicily anchor block displacements induced by increasing cable forces

\subsection{Permanent displacements of anchor blocks induced by earthquake loading}

Permanent displacements induced by earthquake loading in the anchor blocks were evaluated with a rigid-block calculation (Newmark, 1965) modified to account for the progressive mobilisation of the passive earth resistance at the front of the block.

Referring to the simple scheme of Figure 11, the forces acting on the block are the passive $R_{\mathrm{p}}$ and the active $S_{\mathrm{a}}$ earth thrusts, mobilised at the front and at the rear of the block; the resultant of the shear stresses $T_{\mathrm{L}}$ developed along the block sides; the inertia force of the block $K \cdot W$, proportional to its weight through the seismic coefficient; and the cable force $T$. Looking at the longitudinal section of the block, $\alpha$ is the inclination of the sliding plane, $i$ is the inclination of the cable forces, $\varphi_{\mathrm{s}}^{\prime}$ is the friction angle at the base of the block and the inertia force of the block acts with an inclination $\theta$.
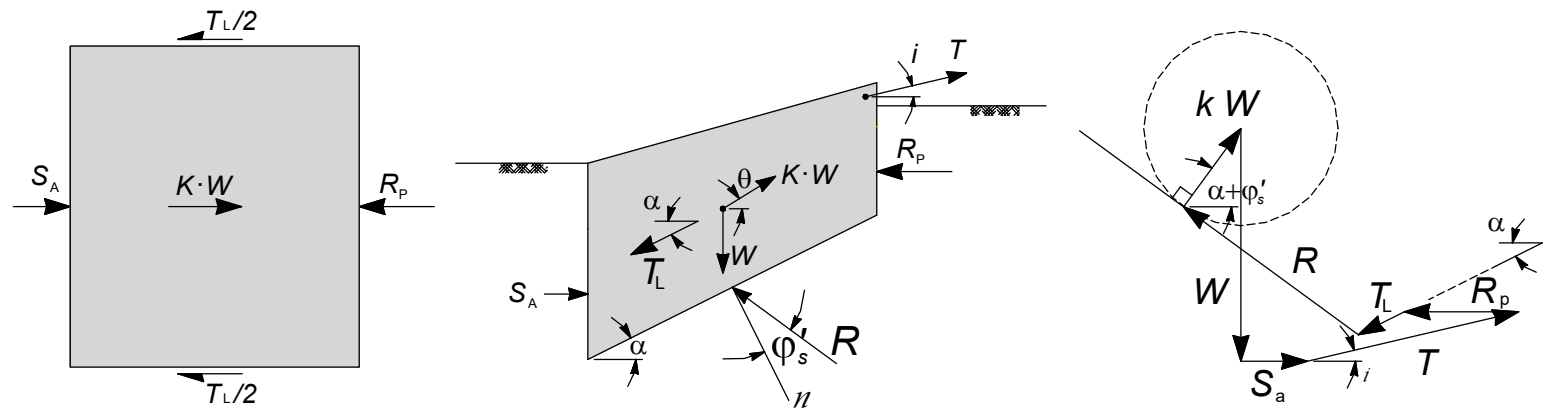

Figure 11. Anchor block scheme and pseudostatic forces

In a sliding block analysis, the critical seismic coefficient $K_{\mathrm{c}}$ is first computed using the pseudostatic approach as the minimum value of the seismic coefficient $K$ corresponding to 
limit equilibrium $\left(F_{\mathrm{s}}=1\right)$. For the case at hand, earthquake-induced displacement occurs along a sliding surface that depends on the shape of the anchor block and on the inclination of the forces $T$ applied by the bridge cables. The average inclination $\alpha$ of the sliding mechanism was evaluated through static 3D push-over analyses in which the cable forces were progressively increased up to full mobilisation of soil strength.

It is assumed that all the forces contributing to the sliding resistance are activated for a very small displacement, except the passive resistance in front of the wall, that develops gradually with the block displacement, as computed from the static 3D FE analyses. Then, the following expression can be obtained from equilibrium consideration:

$$
\begin{aligned}
& T \cos (\alpha-i)-W^{\prime} \sin \alpha+K_{\mathrm{c}} \cdot W \cos (\alpha-\theta)+ \\
& -\left[W^{\prime} \cdot \cos \alpha+T \sin (\alpha-i)+K_{\mathrm{c}} \cdot W \sin (\alpha-\theta)\right] \tan \varphi_{\mathrm{s}}^{\prime}-T_{\mathrm{L}}-\left[R_{\mathrm{p}}\left(d_{0}^{\prime}\right)-S_{\mathrm{aE}}\left(K_{\mathrm{c}}\right)\right] \cos \alpha=0
\end{aligned}
$$

where $W^{\prime}$ is the buoyant weight of the anchor block, and $R_{\mathrm{p}}\left(d_{0}^{\prime}\right)$ is the passive force corresponding to the displacement $d_{0}^{\prime}$ induced by the static cable forces. The free body diagram plotted in Figure 11 shows that the minimum inertial force $K \cdot W$ is normal to the soil reaction $R$, thus acting with an angle $\theta=\alpha+\varphi_{\mathrm{s}}^{\prime}$ with respect to the sliding surface. The critical seismic coefficient $K_{\mathrm{c}}$ is derived solving iteratively equation (8), in which $S_{\mathrm{aE}}\left(K_{\mathrm{c}}\right)$ is computed from the lower bound solution derived by Lancellotta (2007) and the inclination $\alpha$ of the sliding surface is taken equal to the sliding direction obtained by the FE analyses.

Conservative assumptions were adopted to compute the shear stress $\tau=\sigma_{n}^{\prime} \cdot \tan \varphi_{\text {s }}^{\prime}$ acting along the sides of the anchor block. Specifically, to minimise the effective normal stress acting on the vertical sides, active limit conditions were assumed behind the side diaphragm walls, assuming $\varphi^{\prime}=40^{\circ}$ for the active earth pressure coefficient $K_{\mathrm{a}}$, and a reduced value $\varphi_{\mathrm{S}}^{\prime}=30^{\circ}$ at the soil - side wall interface. Similarly, a safe estimate of the active earth pressure $S_{\mathrm{aE}}(K)$ acting at the rear of the block was obtained by neglecting the friction at the block-soil interface $(\delta=0)$. The shear strength at the base was computed using the constant-volume angle of friction $\varphi^{\prime}{ }_{\mathrm{cv}}=38^{\circ}$ to account for strength decay during sliding.

The passive resistance $R_{\mathrm{p}}$ increases progressively as the earthquake-induced displacements cumulate, starting from the static value activated by the cable forces (Fig. 12b). The increase of $R_{\mathrm{p}}$ with the permanent displacement $d$ induced by the seismic loading was described through the reaction of a non linear spring of stiffness $k_{\mathrm{d}}(d)$ (Fig. 12a) calibrated as follows: (a) the progressive increase of the total passive earth thrust $R_{\mathrm{p}}\left(d^{\prime}\right)$ with increasing block displacement was computed through a $3 \mathrm{D}$ static push-over analysis (full circles in Fig. 12b); (b) the part of the curve in excess to the static condition $\Delta R_{\mathrm{p}}=\left[R_{\mathrm{p}}\left(d^{\prime}\right)-R_{\mathrm{p}}\left(d^{\prime}\right)\right]$ was fitted with 
a hyperbole (dashed line in Fig. 12b); (c) the relationship between $\Delta R_{\mathrm{p}}$ and block displacements, that is the results of a static push-over computation, was scaled to account for the seismic inertial forces to reach, at large displacements, the lower bound pseudo-static passive thrust $R_{\mathrm{pE}}\left(K_{\mathrm{c}}\right)$ provided by the Lancellotta (2007) solution (full line in Fig. 12b).

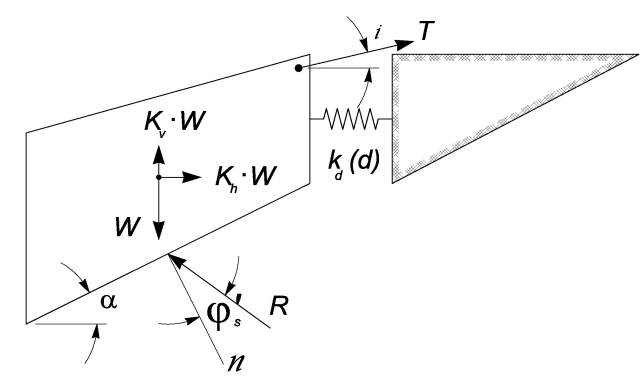

(a)

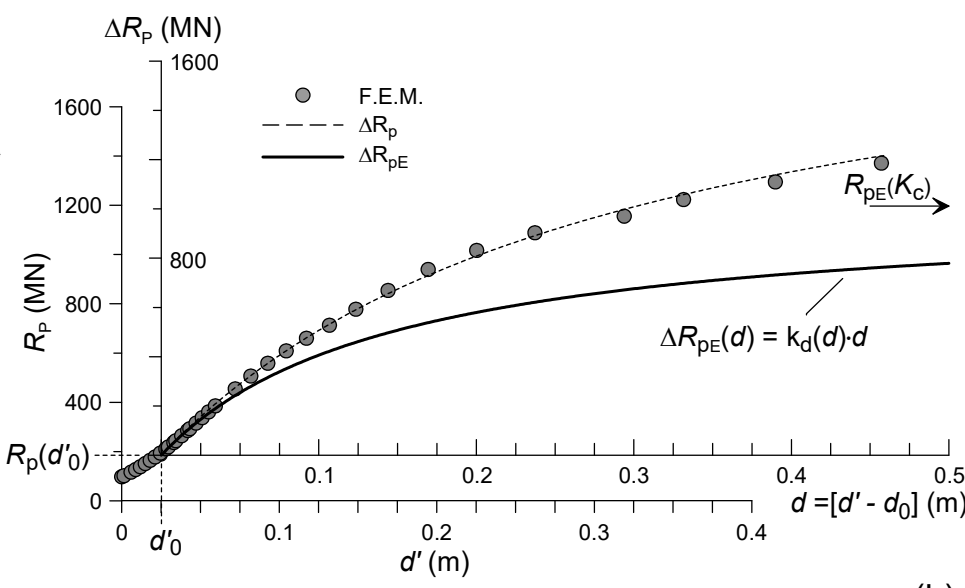

(b)

Figure 12. Mobilisation of passive earth resistance with earthquake-induced block displacements

The contribution of $\Delta R_{\mathrm{pE}}(d)=k_{\mathrm{d}}(d) \cdot d$ was inserted explicitly into the equation of relative motion that, for $\theta=\alpha+\varphi^{\prime}$ s provides:

$$
\frac{W}{g} \ddot{d}(t)+k_{\mathrm{d}}(d) \cdot d(t)=W\left\{\left[K_{\mathrm{h}}(t)+K_{\mathrm{v}}(t) \cdot \tan \left(\alpha+\varphi_{\mathrm{s}}^{\prime}\right)\right] \cos \left(\alpha+\varphi_{\mathrm{s}}^{\prime}\right)-K_{\mathrm{c}}\right\} \frac{1}{\cos \varphi_{\mathrm{s}}^{\prime}}
$$

Integration of equation (9) was carried out according to the Newmark (1965) scheme, updating continuously the spring stiffness as the computed block displacements increased.

The computations were performed using 22 records of real seismic events selected from the PEER database specifying values of magnitude in the range of 6.5 to 7.28 and peak ground acceleration in the range of one half to twice the design peak acceleration for the ultimate limit state $\left(a_{\mathrm{p}}=0.58 \mathrm{~g}\right)$. Specifically, the records were characterised by values of peak ground acceleration of 0.294 to $0.789 \mathrm{~g}$, Arias intensity $I_{\mathrm{A}}=0.799-7.589 \mathrm{~m} / \mathrm{s}$, significant duration $T_{\mathrm{D}}=6.09-70.53 \mathrm{~s}$ and predominant periods $T_{\mathrm{p}}$ of 0.088 to $2.341 \mathrm{~s}$. For each record, the horizontal component was combined with the corresponding vertical component, the time histories were scaled to $a_{\mathrm{p}}=0.58 \mathrm{~g}$, and the computations were carried out considering also the inverse time histories $a_{\text {inv }}(\mathrm{t})=-a(\mathrm{t})$.

The bar chart of Figure 13a reports the permanent displacements computed for the Sicily 
anchor block using the acceleration time histories mentioned above and assuming the sliding mechanism obtained from the 3D FE analyses, characterised by an inclination $\alpha=14^{\circ}$. The maximum displacement computed for the Sicily block, $d_{\max }=25 \mathrm{~mm}$, is in good agreement with the results of a set of $2 \mathrm{D}$ dynamic interaction analyses that are discussed in the next section. As some preliminary analyses showed that block displacements increase with decreasing inclination of the sliding mechanism, computations were repeated assuming that sliding occurs along a plane with the inclination of the rear part of the block base, equal to $\alpha=8^{\circ}$ (Fig. 13b). Even in this case, the seismic performance of Sicily anchor block is satisfactory, as the maximum computed displacement $d_{\max }=58 \mathrm{~mm}$ is equal to only $0.06 \%$ of the length of the cable spanning between the anchor block and the tower.
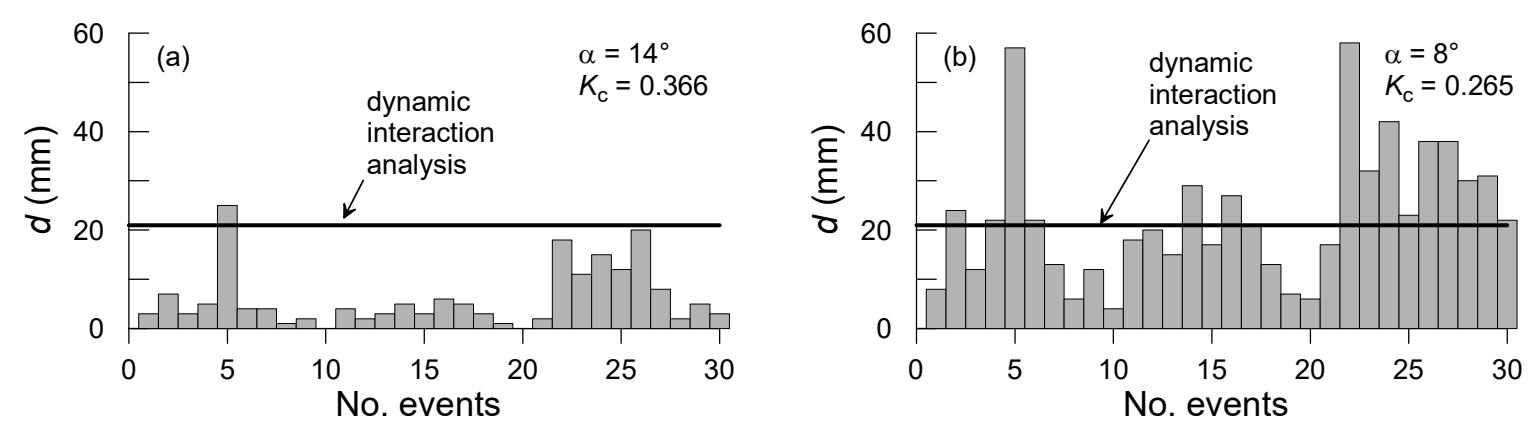

Figure 13. Sicily anchor block: earthquake-induced displacements computed using a modified sliding block analysis

\section{SEISMIC ANALYSIS OF SOIL-STRUCTURE INTERACTION}

At a final stage, dynamic soil-structure interaction analyses were carried out to evaluate the seismic performance of the bridge foundations (Callisto et al., 2013). The computed time histories of displacements and rotations were also employed in time-domain structural analyses of bridge superstructure.

For these soil-structure interaction analyses, two scenario earthquake records were provided by the seismological consultancy staff, that were deemed representative of the near-field effects produced by the 1908 Messina earthquake (with an estimated moment magnitude of 7.1): the acceleration time histories corresponding to record N14 of Kocaeli earthquake (1999), at Arcelik station, and those corresponding to record DHFS of New Zealand earthquake (2010), at Darfield station. The New Zealand record appears to be more severe than the Arcelik one, as it is characterised by higher values of maximum horizontal acceleration, Arias Intensity and duration (Table 2). 
Table 2. Input scenario earthquakes for dynamic analyses of soil-structure interaction

\begin{tabular}{|c|c|c|c|c|c|c|c|c|}
\hline earthquake & station & record & comp & $\begin{array}{c}a_{\max } \\
(g)\end{array}$ & $\begin{array}{c}I_{\mathrm{A}} \\
(\mathrm{m} / \mathrm{s})\end{array}$ & $\begin{array}{l}T_{\mathrm{D}} \\
(\mathrm{s})\end{array}$ & $\begin{array}{c}T_{\mathrm{p}} \\
\text { (s) }\end{array}$ & $\begin{array}{l}T_{\mathrm{m}} \\
(\mathrm{s})\end{array}$ \\
\hline \multirow{3}{*}{$\begin{array}{l}\text { Kocaeli } \\
(1999)\end{array}$} & \multirow{3}{*}{ Arcelik } & \multirow{3}{*}{ N14 } & $H_{\max }$ & 0.244 & 0.55 & 7.43 & 0.40 & 0.70 \\
\hline & & & $H_{\text {min }}$ & 0.137 & 0.32 & 7.75 & 0.44 & 0.92 \\
\hline & & & V & 0.203 & 019 & 8.04 & 0.10 & 0.36 \\
\hline \multirow{3}{*}{$\begin{array}{c}\text { New Zealand } \\
(2010)\end{array}$} & \multirow{3}{*}{ Darfield } & \multirow{3}{*}{ DHFS } & $H_{\max }$ & 0.480 & 2.67 & 20.90 & 0.20 & 0.43 \\
\hline & & & $H_{\text {min }}$ & 0.450 & 2.39 & 29.96 & 0.18 & 0.46 \\
\hline & & & $V$ & 0.307 & 1.95 & 25.54 & 0.10 & 0.40 \\
\hline
\end{tabular}

The analyses were carried out in plane strain conditions using the code FLAC (Itasca, 2005), and following a two-stage procedure. A static analysis was first performed to reproduce the pre-earthquake stress state, using a linearly elastic - perfectly plastic soil model; in this stage, the initial effective stress and pore water pressure were computed and a construction stage was included in which the foundation elements were loaded by the static actions transmitted by the bridge. In the following stage the seismic analyses were carried out in the time-domain including simplified structural models of the bridge towers and using a non-linear soil model with hysteretic damping implemented in FLAC. The usual boundary conditions were applied in the static analysis, while in the seismic analysis the constraints on the vertical sides were removed and the free-field FLAC boundary conditions were activated.

In the analyses, the actual 3D foundations were replaced by equivalent plane-strain strip footings. To this purpose, an equivalent length, normal to the analysis plane, was evaluated for each foundation system to scale the weight and the stiffness of the structural elements. The equivalent length was defined as the length producing the same displacements in a simple static 2D computation with a linearly elastic continuum.

The calculations were carried out in terms of effective stresses; since companion liquefaction analyses indicated negligible excess pore water pressure below the jet-grouted areas planned for the tower foundations, any dynamic increase in pore water pressure was neglected in the analyses.

Four different calculation grids were used for each shore: one longitudinal grid, parallel to the bridge, and three transverse grids, orthogonal to the bridge, one for each main structure (tower, terminal structure and anchor block). The longitudinal grid for the Sicily shore, a portion of which is shown in Figure 14, includes the tower, the terminal structure and the anchor block, for a total width of $1680 \mathrm{~m}$, and extends to the bottom of Messina Gravel, at about $215 \mathrm{~m}$ of depth. The size of the grid zones varies from 4 to $10 \mathrm{~m}$ for shear wave velocities in the range of 250 to $1100 \mathrm{~m} / \mathrm{s}$, allowing the transmission of frequencies lower than about $16 \mathrm{~Hz}$. 


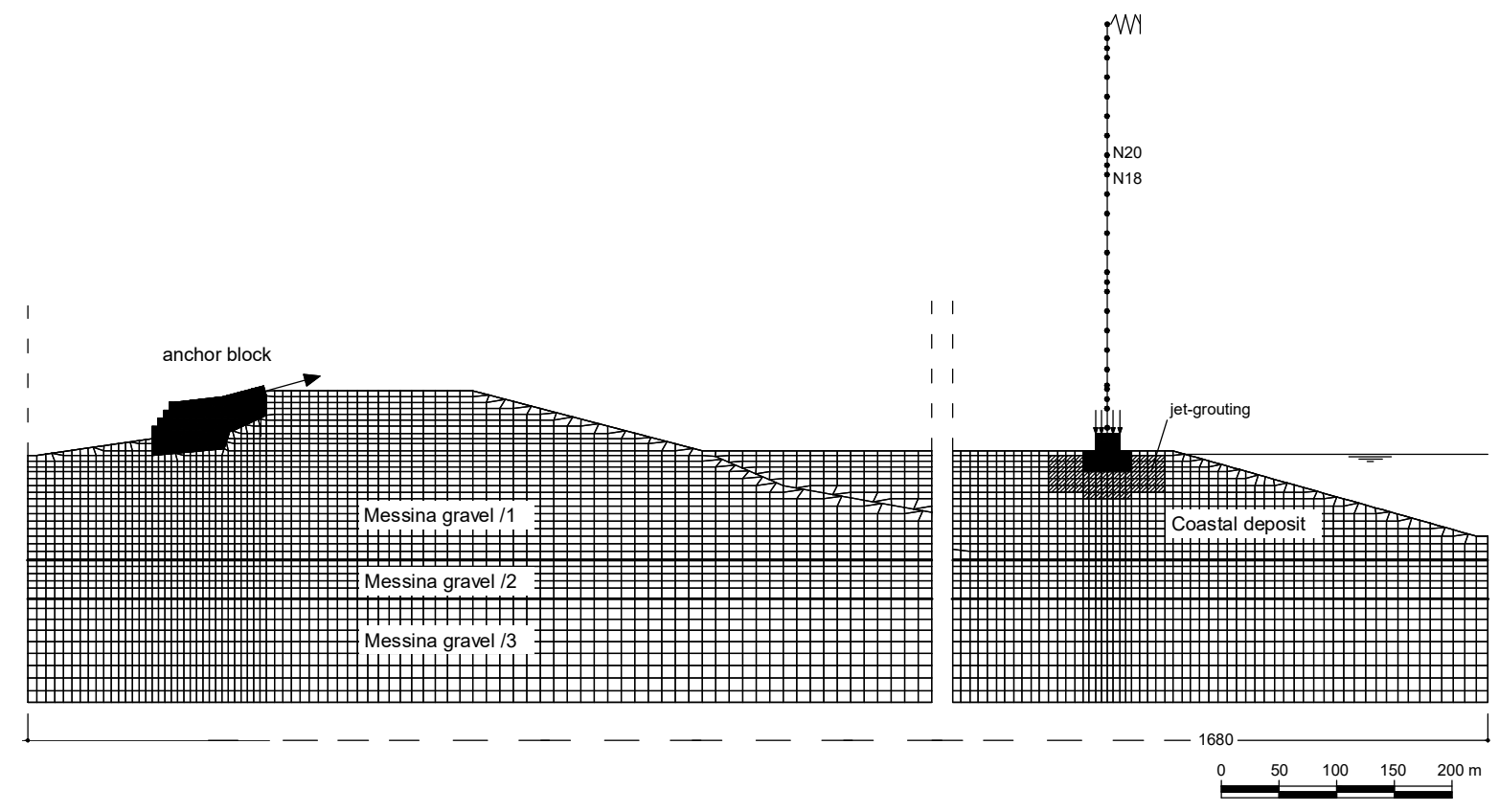

Figure 14. Portion of the longitudinal finite difference grid for the Sicily tower

Simplified structural models of the towers were included in the longitudinal and transverse calculation grids, since the dynamic response of the superstructure can influence substantially the soil-structure interaction. These structural models included a representation of the restraint provided by the suspension system through simple linear elastic springs that, because of the very large cable natural period, connect the top of each tower to a fixed point. (Fig. 14).

The properties of the simplified models of the tower were identified to reproduce the first vibration mode of the tower structure. To this purpose, additional plane strain dynamic analyses of isolated simplified models of the tower were performed using FLAC and the results were compared with those of structural models of the tower consisting of elastic beams elements with concentrated masses. In these identification analyses a sinusoidal displacement history with a linear continuous sweep of frequency $(0.2$ to $2 \mathrm{~Hz})$ was applied to the base of the models and the natural frequency of vibration was evaluated from the Fourier displacement spectra computed at selected nodes of the models. The first modal shape was also recovered at the time instant in which the displacement of the tower was maximum. Figure 15a-c show the comparison of longitudinal responses computed at tower nodes N18 and N20 (see Fig. 14): in Figure 15a the input displacement time history is plotted together with those computed at nodes N18 and N20; in Figure 15b the first peak identifies the first natural frequency of the simplified FLAC model of the tower that is the same as that of the structural model, equal to $0.39 \mathrm{~Hz}$; Figure $15 \mathrm{c}$ compares the first modal shape of the simplified tower-model, obtained by the FLAC analysis at a frequency of $0.39 \mathrm{~Hz}$, with that computed for the detailed structural model, again showing a very good agreement. 

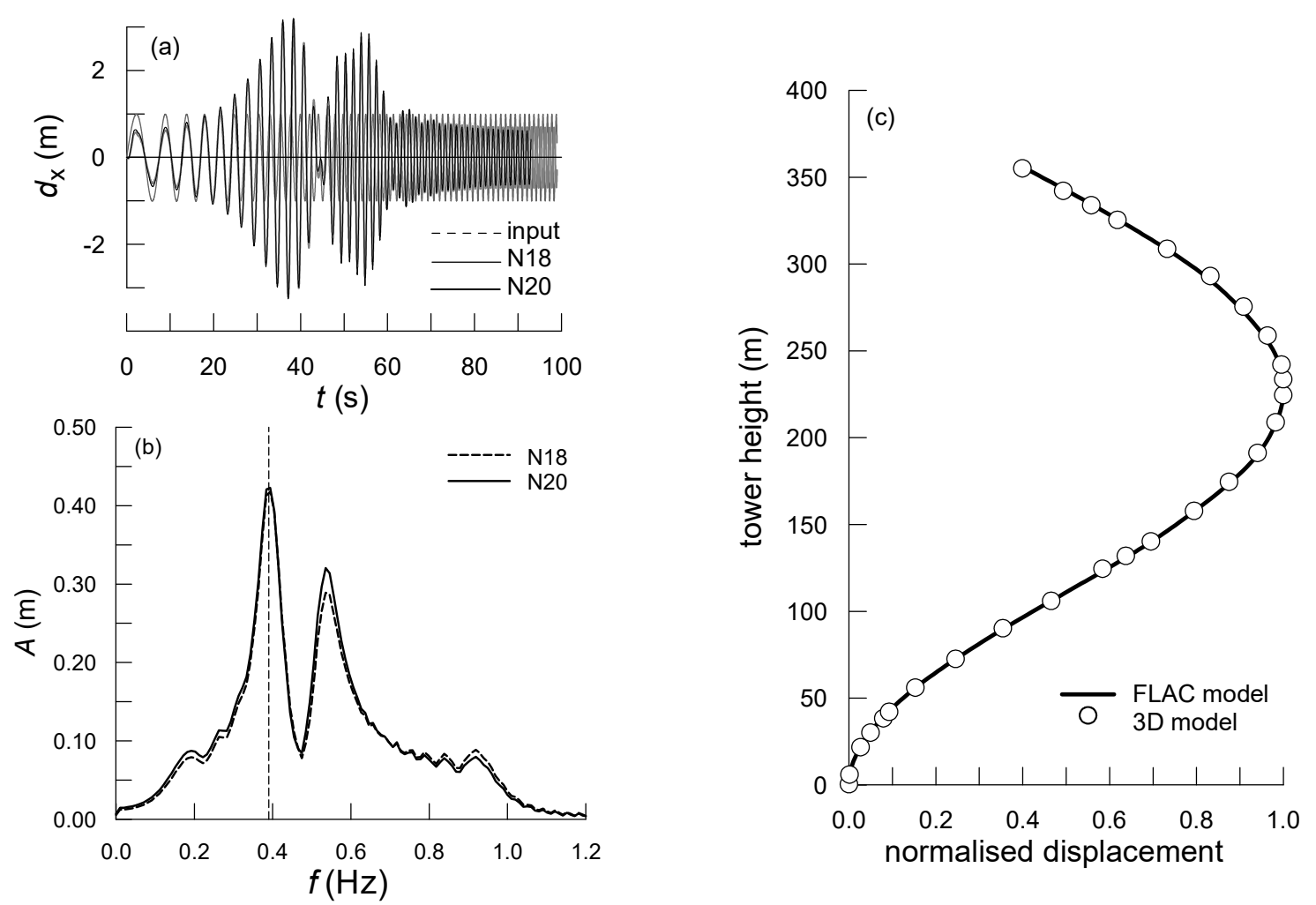

Figure 15. Longitudinal analysis of Sicily shore - dynamic response of the simplified tower model: (a) input frequency sweep and displacement time histories at selected nodes; (b) Fourier response spectra; (c) first modal shape of the tower

In the dynamic analyses, the cyclic soil behaviour was described through a hysteretic constitutive model available in FLAC, in which generalised Masing rules (Masing, 1926) are applied at each strain reversal to produce hysteresis loops. The model requires the small-strain shear modulus $G_{0}$ and a modulus decay curve that describes the reduction of the shear modulus with shear strain $\gamma$. Small-strain shear modulus was again calibrated on results of cross-hole tests and was described as a function of mean effective stress $p^{\prime}$. The Messina Gravel was subdivided in sub-layers to better reproduce the variation of soil stiffness with depth (see Fig. 14).

For the Coastal Deposits and the Messina Gravel, the relationship provided by the FLAC model to describe the modulus decay was calibrated on the results obtained by Tanaka et al. (1987) and on the curve provided by Seed and Idriss (1970) for coarse-grained soils. Figure 16 shows a satisfactory comparison between the target curve and the modulus decay predicted by the model, while the computed damping $D$, that cannot be calibrated as it is a model response, is somewhat higher than the experimental data for relatively large values of shear strain $\gamma>0.01 \%$. Preliminary one-dimensional free-field comparisons between the predictions of the hysteretic model and those of an equivalent linear calculation with a visco-elastic 
model (Schnabel et al., 1972) yielded a reasonable agreement and showed that values of $\gamma$ larger than $0.01 \%$ were only locally and instantaneously attained for the seismic input used in the analyses.
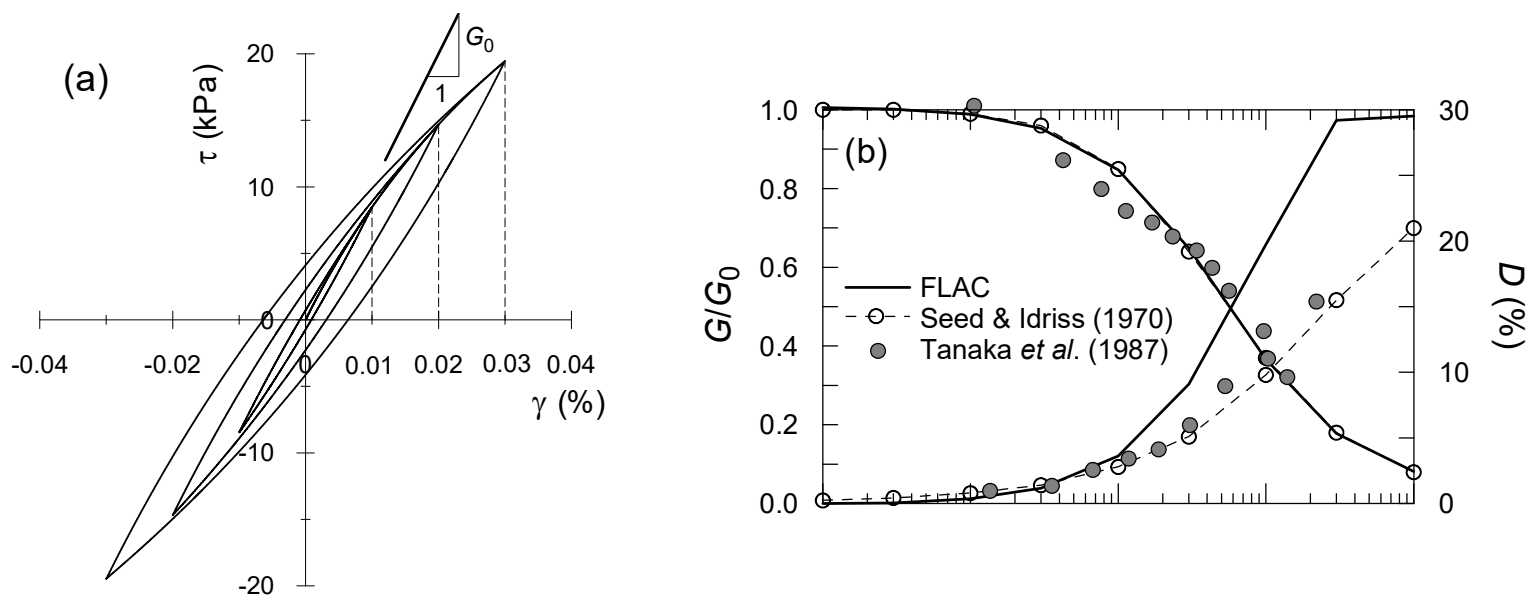

Figure 16. Calibration of the hysteretic soil model for Coastal Deposits and Messina Gravels/1

The seismic stages of the analyses were performed applying horizontal and vertical acceleration time histories to the bottom boundary of the 2D computation grid, that accounted for the finite stiffness of the deposits encountered at larger depths (Callisto et al. 2013). Specifically, the selected earthquakes were taken as representative of outcrop motions and the seismic inputs applied at the base of the 2D models were obtained by 1D FLAC deconvolution to the depth of the bedrock and subsequent $1 \mathrm{D}$ upward propagation to the elevation corresponding to the bottom of the 2D computation grid. De-convolution for timedomain analyses was based on the procedure by Joyner and Chen (1975).

De-convolution and upward propagation were carried out twice for each earthquake record, combining the vertical component with either the maximum or the minimum horizontal component of acceleration. The vertical and horizontal accelerations computed in the 1D numerical analyses at the depth corresponding to the base of the 2D model were finally used as input motions for the plane strain seismic analyses. Four combinations of input records were applied at the base of each grid, considering both signs of the two horizontal components.

The results of the soil-structure interaction analyses were expressed in terms of time histories of displacement and rotation at selected points of the anchor blocks, the tower foundations and the terminal structures. In the following only a few typical results are shown, the study being presented in a more complete form by Callisto et al. (2013).

Figure 17 shows the time-histories of the Sicily and Calabria tower foundations, computed in 
the longitudinal direction using the worst combinations obtained from the Darfield records; in both cases permanent rotations are directed towards the sea, and those for the Calabria tower are larger. Permanent deformations are generated mostly during the final stage of the strong motion, between about $20 \mathrm{~s}$ and $30 \mathrm{~s}$.

The maximum permanent displacements and rotations computed in the longitudinal direction using the four combinations for the Darfield record are plotted for both the Sicily and Calabria shores in Figure 18. All deformations are directed towards the centre of the Strait. Specifically, the tower foundations move towards the sea by about $40 \mathrm{~mm}$ in Sicily and by about $30 \mathrm{~mm}$ in Calabria. The maximum tower rotation, equal to $0.015^{\circ}$, is computed for the Calabria shore; this is due to the local soil profile that includes an inclined contact between the upper granular deposits and the Pezzo Conglomerate. In any case, the maximum computed tower inclination, equal to $0.26 \%$ is lower than the limit of $1 \%$ specified in the design. The maximum displacements computed for the anchor blocks in the longitudinal direction are equal to about $20 \mathrm{~mm}$, this resulting in a cable shortening of only $0.025 \%$ of the cable length in between the anchor block and the tower.

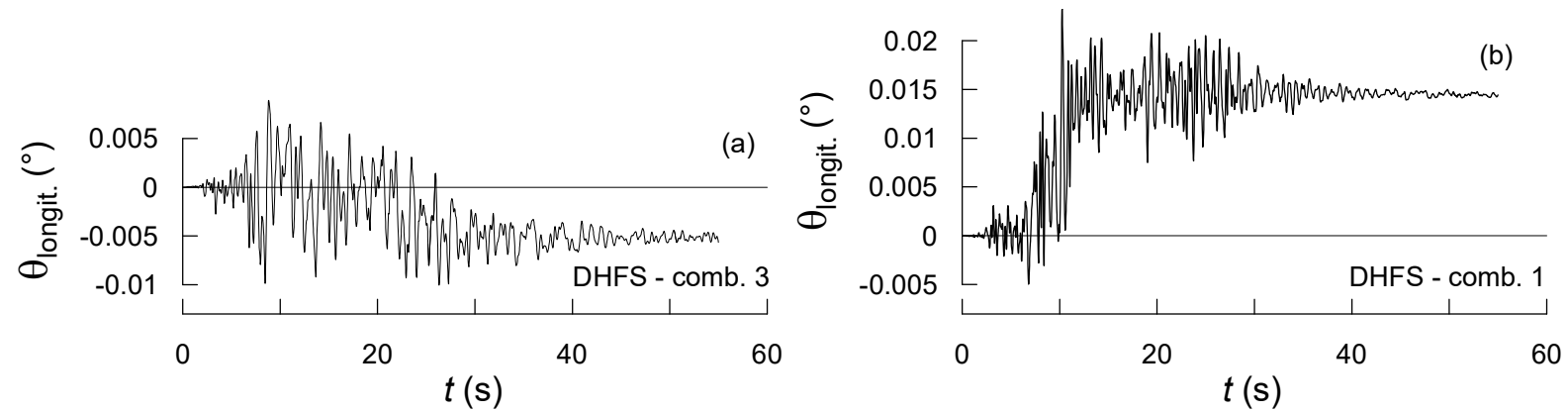

Figure 17. Computed time histories of rotation: (a) Sicily tower; (b) Calabria tower
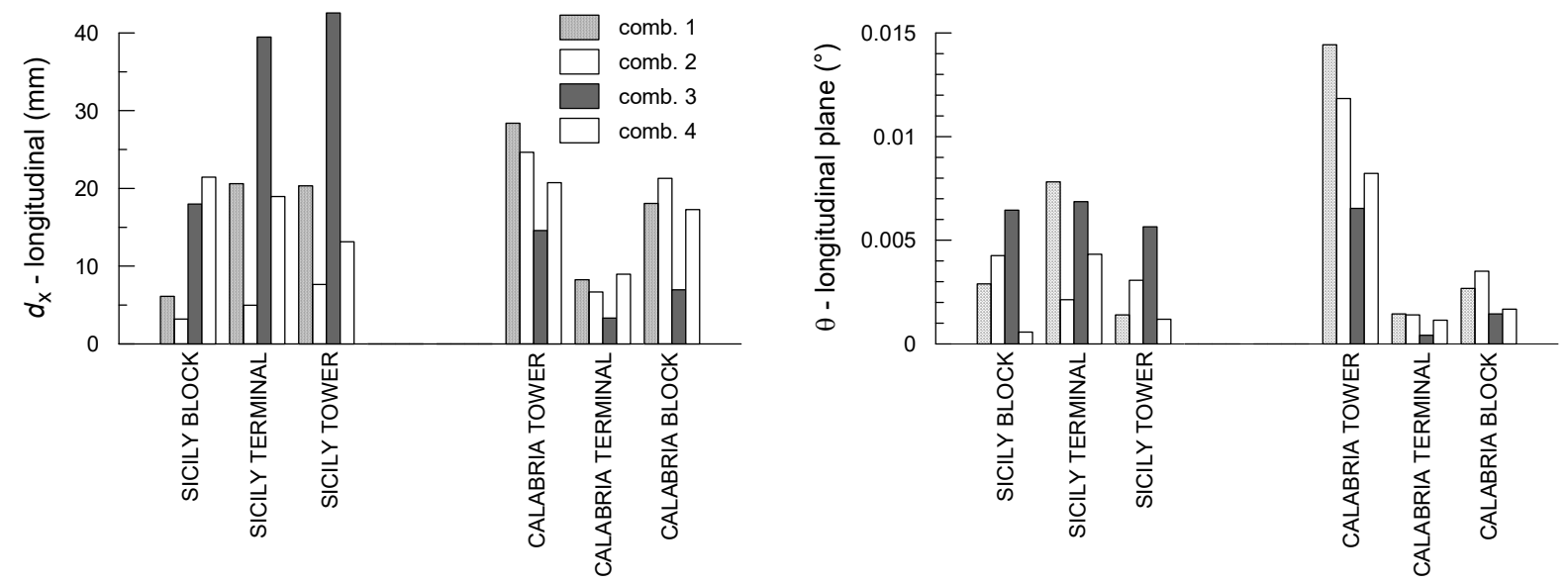

Figure 18. Computed maximum displacements and rotations in the longitudinal direction - DHSF records 


\section{CONCLUSIONS}

An evaluation of the seismic performance of the foundations of the Messina Strait bridge included numerous activities, characterised by different degrees of complexity and robustness. The entire process hinged on a careful geotechnical characterisation for the coarse-grained soils encountered on both shores, that was achieved using advanced in situ testing, sophisticated sampling techniques and both monotonic and cyclic laboratory tests on large samples.

The behaviour of the main foundation elements was firstly evaluated through static, non linear three-dimensional finite element analyses; in a second stage, simplified dynamic computations were performed, consisting in modified sliding block calculations for the anchor blocks. Finally, a number of full soil-structure interaction analyses were carried out, in which simplified structural models of the Towers were explicitly coupled with a non linear model for the subsoil.

Each computation model had its own advantages but required corresponding simplifying hypotheses: the static models reproduced the actual three-dimensional layout of the foundation elements and simulated closely the construction stages, but obviously the earthquake could be simulated only through static equivalent forces; the sliding block calculations included inertial effects but assumed that the movements of anchor block occur strictly by sliding along a fixed plane; the soil-structure interaction analyses reproduced to some extent the dynamic interaction of the soil deposit with the foundation elements and with the superstructure, but were carried out under equivalent plane-strain conditions. It was encouraging to see that the results produced by these very different approaches are reasonably consistent. On the whole, the estimated seismic performance of the bridge was deemed appropriate for the prescribed earthquake scenario.

\section{AKNOWLEDGEMENTS}

The Authors wish to acknowledge Prof Michele Jamiolkowski for the fruitful and stimulating discussions along the development of the study; they are also indebted Dr Luca Masini and Dr Riccardo Conti for performing some of the numerical analyses.

\section{REFERENCES}

Baldi, G., Bellotti, R., Ghionna, V., Jamiolkowski M. and Pasqualini, E. (1985). Penetration resistance and liquefaction of sands. Proc. XI Int. Conf. on Soil Mech. and Found. Engng., ICSMFE San Francisco, 4: 1891-1896. 
Bolton M.D. (1986). The strength and dilatancy of Sands. Géotechnique, 36 (1), 65 - 78.

Callisto L., Rampello S., Viggiani G. (2013). Soil structure interaction for the seismic design of the Messina Strait Bridge. Soil Dynamics and Earthquake Engineering, 52, 103 - 115.

Cubrinovski M., Ishihara K. (1999). Empirical Correction between SPT-N Value and Relative Density for Sandy Soils. Soils and Foundations, 39 (5), 61 - 71.

Fioravante V., Giretti D., Jamiolkowski M. and Rocchi G.F. (2012). Triaxial tests on undisturbed gravelly soils from the Sicilian shore of the Messina Strait. Bulletin of Earthquake Engineering DOI 10.1007/S10518-012-9374-7, published online 21 Septembers 2012.

Foti, S., Lai, C.G. and Lancellotta, R. (2002). Porosity of fluid saturated porous media from measured seismic wave velocities. Géotechnique, 52 (5): 359-373.

Itasca (2005). FLAC: Fast Lagrangian Analysis of Continua. v.5.0 User's Manual. ITASCA, USA.

Jamiolkowski M. and Lo Presti D. (2002). Geotechnical characterisation of Holocene and Pleistocene Messina sand and gravel deposits. Proc. International symposium on Characterisation and Engineering Properties of Natural Soils, Singapore, Swets and Zeitlinger, 1087-1119.

Joyner, W.B., and Chen, A.T.F. (1975). Calculation of nonlinear ground response in earthquakes. Bulletin of the Seismological Society of America, 65 (5), 1315-1336.

Lancellotta, R. (2007). Lower-bound approach for seismic passive earth resistance. Géotechnique, 57 (3): 319-321.

Masing, G. (1926). Eigenspannungen und Verfertigung bim Messing. Proceedings 2nd Int. Congress on Applied Mechanics, Zurich.

Newmark N.M. (1965). Effects of earthquakes on dams and embankments. Géotechnique, 15 (2): 139160.

Schanz T., Vermeer P.A. and Bonnier P.G. (1999). Formulation and verification of the Hardening Soil model. Proc. Plaxis Symposium on Beyond 2000 in Computational Geotechnics, Amsterdam, 281-296.

Schnabel, P.B., Lysmer, J., and Seed, H.B. (1972). SHAKE, a computer program for earthquake response analysis of horizontally layered sites. Report: Earthquake Engineering research Center, University of California, Berkeley.

Seed, H.B., and Idriss, I.M. (1970). Soil moduli and damping factors for dynamic analysis. Report No. EERC 70-10, University of California, Berkeley.

Tanaka Y., Kudo Y., Yoshida Y. \& Ikemi M. (1987). A study on the mechanical properties of sandy gravel - dynamic properties of reconstituted samples. Central Research Institute of Electric Power Industry, Report U87019. 